\title{
Familial infantile spasms and hypsarrhythmia associated with leucodystrophy
}

\author{
A. BIGNAMI, F. MACCAGNANI, M. ZAPPELLA, AND A. H. TINGEY \\ From the Institute of Morbid Anatomy, the Clinic for Neurological and Mental Disorders, \\ and the Paediatric Clinic, the University of Rome, and the Burden \\ Neuropathological Laboratory, Frenchay Hospital, Bristol
}

In an Italian family, two little girls were affected by a condition characterized by infantile spasms, hypsarrhythmia, and rapid motor deterioration, resulting in death in the second year of life. A pathological study of one of them has shown sudanophilic leucodystrophy. The occurrence of this form of epilepsy in siblings is extremely rare and its association with sudanophilic leucodystrophy has not been reported in the literature to date.

\section{CASE REPORTS}

The two sisters who form the subject of this study were born a year apart. An older brother has perfect health. No evidence was obtained of neurological or metabolic disease in any other member of the family.

The elder of the affected children was delivered spontaneously, the result of an uncomplicated full-term pregnancy. The nebnatal period appeared normal, as was psychomotor development up to 9 months of age, when the baby was able to sit alone, and showed a normal interest in her surroundings.

Flexion spasms first appeared at 9 months in attacks lasting about 15 to 20 minutes, followed by crying. These fits were initially present only on waking. They were predominantly in flexion but occasionally also in extension. An E.E.G. during spontaneous sleep showed intense epileptic activity on all leads with spikes, polyspikes, and slow waves mixed in a disorderly way (Fig. 1a). On waking, paroxysmal bursts of slow and sharp activity were seen (Fig. 1b). The generalized bursts of dysrhythmia on waking were often simultaneous with the myoclonic jerks. The records were considered compatible with hypsarrhythmia.

At this stage the child was less responsive, moved less than before, and showed generalized hypotonus. The $\mathrm{FeCl}_{3}$ urine test for phenylpyruvic acid was negative. In the following months myoclonic fits became more intense and more frequent and were observed at various times during the day. At the same time, the psychomotor deterioration was progressively more evident, to the point at which the child was almost entirely motionless and unresponsive.

The E.E.G. was repeated when the baby was 15 months old, with similar results. She died at 18 months of age in status epilepticus and hyperthermia. There was no post-mortem examination.

The second affected child was born two weeks postmature. The neonatal period was apparently normal. During the first year of life, the parents noticed a delay in development and at 11 months she was unable to sit alone and responded very little to stimuli. At this age, flexion spasms appeared first, being more frequent on waking, and after two weeks from the beginning of these symptoms, she was seen in the Neurological Outpatient Department. There she showed very little spontaneous activity, responded but slightly to various stimuli, and appeared to be mentally handicapped. However, there were no specific signs of neurological deficit. The $\mathrm{FeCl}_{3}$ urine test for phenylpyruvic acid was negative. An E.E.G. gave evidence of hypsarrhythmia (Fig. 2).

Treatment with phenobarbital was begun, but after a month there was no improvement in the clinical condition and in the subsequent E.E.G. Treatment with A.C.T.H. was started, but after the first 25 units had been given, a high fever suddenly developed, with status epilepticus, and the child died two days after admission to hospital at the age of 13 months.

\section{PATHOLOGY}

Post-mortem examination of the second affected child revealed a brain of normal size and weight $(940 \mathrm{~g}$.), the convolutions appearing to be normal also. On cutting, the brain appeared oedematous: there was a slight greyish discoloration of the white matter in the cerebral hemispheres, especially in the frontal and occipital poles.

No significant changes were found in the remainder of the post-mortem examination.

\section{HISTOLOGY}

FRONTAL POLE The white matter was pale in myelin preparations and with the Holzer stain there was fibrillary gliosis (Fig. 3). There was slight loss of nerve cells in the superficial cortical layers, with a little marginal gliosis beneath the pial surface in some places. In frozen sections many microglial cells were filled with sudanophilic droplets (Fig. 4) and some blood vessels were cuffed with 
FIG. 1a.
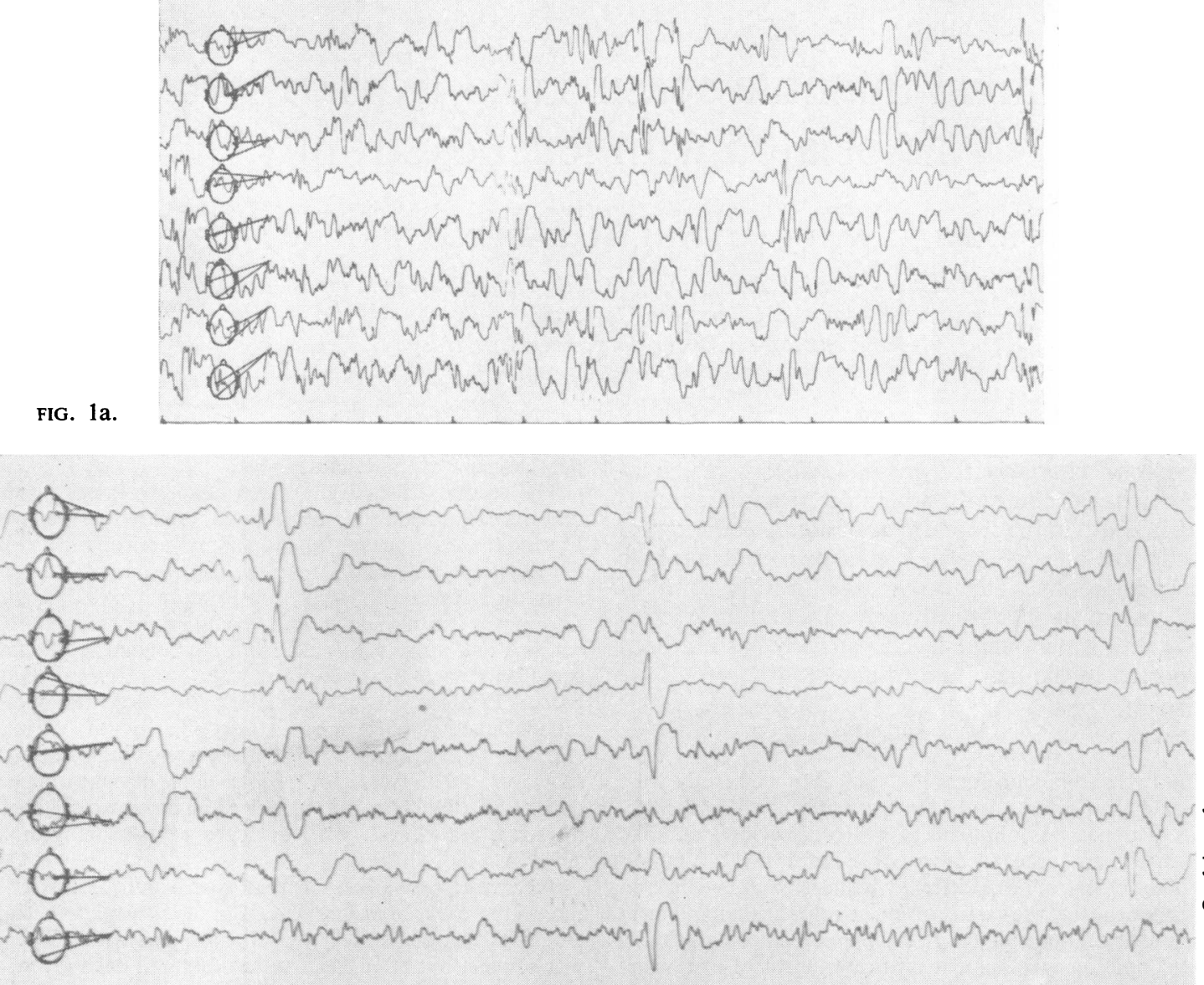

FIG. $1 b$.

FIG. 1a and b. E.E.G. of case 1. Records in this and in Fig. 2 were taken with a time constant of $0.3 \mathrm{sec}$. at $3 \mathrm{~cm} . / \mathrm{sec}$. with a gain of $7 \mu \mathrm{V} / \mathrm{min}$.

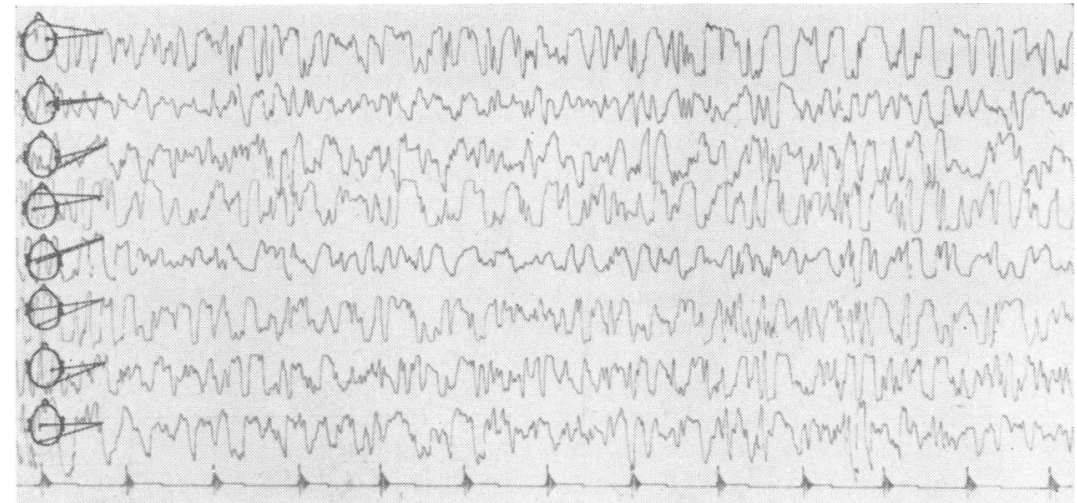

FIG. 2. E.E.G. of case 2. 


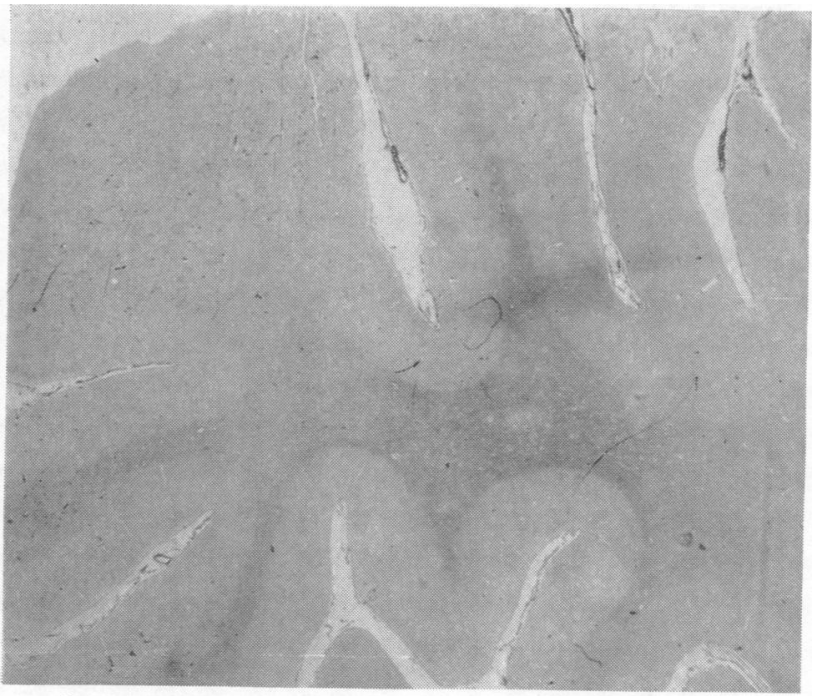

FIG. 3. Gliosis of the white matter in the frontal pole. Holzer (paraffin).

FIG. 4. Phagocytes filled with lipid in the white matter of the frontal pole. Sudan III $\times 70$.

FIG. 5. Demyelination and vacuolation of the white matter in the frontal pole. The deep layers of the cortex are not affected. Spielmeyer $\times 45$.

FIG. 3 .

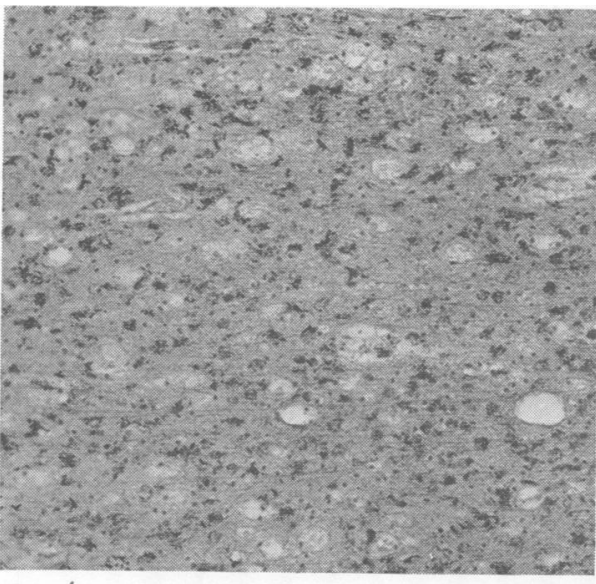

FIG. 4.

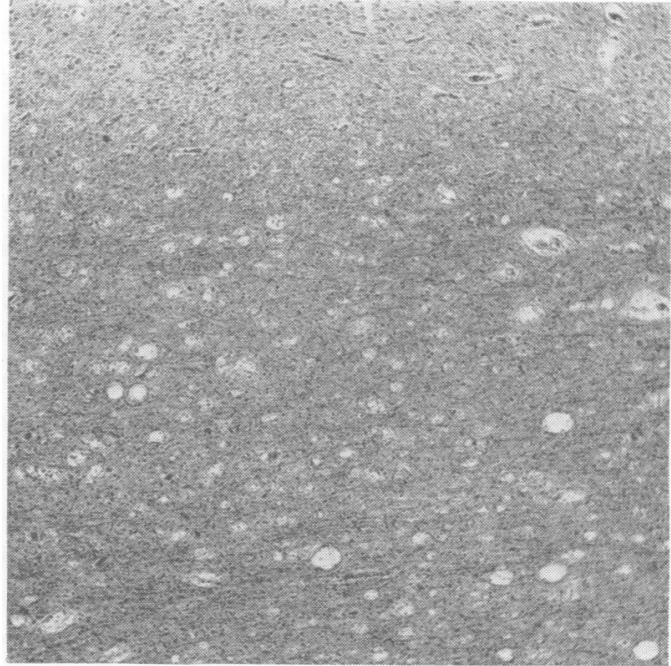

FIG. 5. phagocytes containing fat. The most characteristic feature was diffuse vacuolation of the white matter (Figs. 4 and 5). The vacuoles were larger than those usually seen in cerebral oedema and were not collected in clusters; they seemed completely empty in frozen and in embedded sections except for a little granular debris in some places. Many surviving myelin sheaths showed focal beading and ballooning, but it was impossible to demonstrate that the vacuoles resulted from the distension of these structures. In Gros-Bielschowsky preparations there was severe loss of axons.

TEMPORAL LOBE The white matter was very pale in myelin preparations and there was well-marked fibrillary gliosis with some vacuolation. In Ammon's horn there was severe loss of cells in the Sommer sector and in the end-plate with ischaemic necrosis of the remaining neurones.

FRONTO-PARIETAL REGION The white matter was rather pale in myelin preparations and distinctly vacuolated (Fig. 6) with slight fibrillary gliosis; in frozen sections only a few microglial cells were filled with sudanophilic droplets, and some blood vessels were cuffed with phagocytes containing fat. There was no significant cell loss in the fronto-parietal cortex or in the insula. 


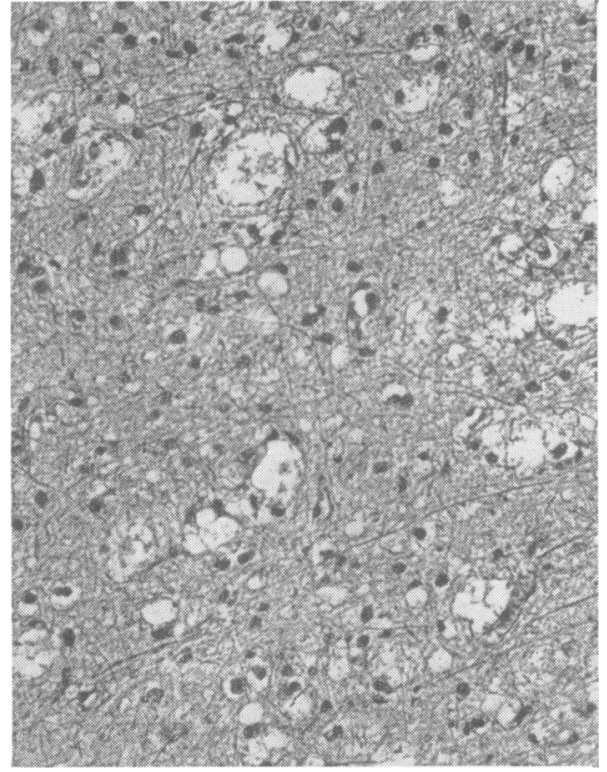

F1G. 6. Vacuolation of the white matter in the parietal lobe. Gros-Bielschowsky $\times 140$ (paraffin).
OCCIPITAL LOBE The external and internal sagittal layers were well myelinated but otherwise the white matter was very pale in myelin preparations, with many vacuoles and many fat-containing microglial cells. There was no significant cell loss in the cortex.

BASAL GANGLIA AND SUBthalamus No significant changes were present in the striatum and pallidum, except for some vacuoles, similar to those seen in the white matter, in the pallidum. The lateral nuclear masses of the thalamus and subthalamic body were finely vacuolated, with vacuoles much smaller than those seen in the white matter. This change was not visible in frozen sections and there was no definite nerve cell loss or gliosis. The corpus callosum, corona radiata, internal capsule, anterior commissure, and the fibre bundles in the putamen, pallidum, thalamus, and subthalamic region were well myelinated.

CEREBELluM A few Purkinje cells showed homogenizing changes. The granular layer was thin and the granules less densely packed than normal (Fig. 7a). No significant changes were present in the dentate nucleus or the white matter.

BRAIN-STEM AND SPINAL CORD There were many fatcontaining microglial cells in the pes pedunculi. The medullary pyramids and pyramidal tracts were poorly myelinated.

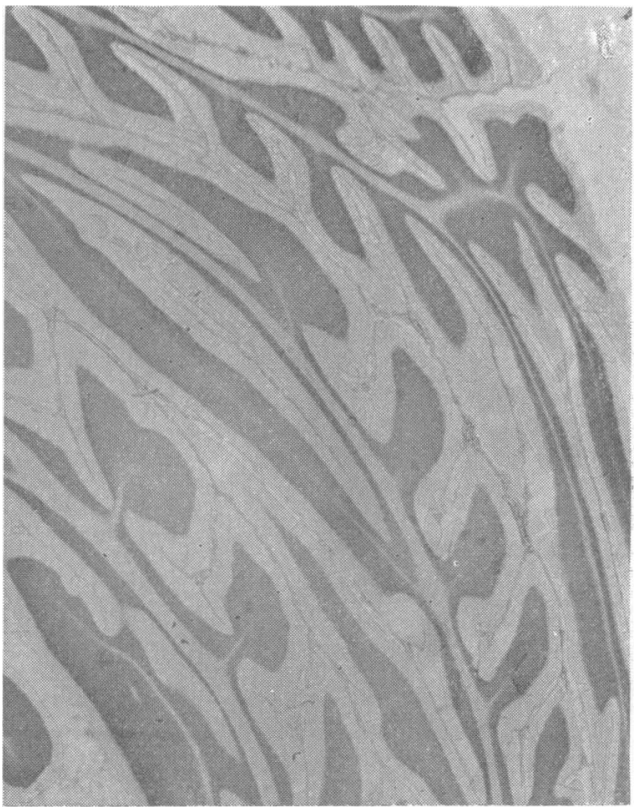

FIG. $7 b$.

FIG. 7. Severe atrophy of the granular layer in the cerebellar cortex (Fig. 7a). Cerebellar cortex in a child (1 year old) who died in status epilepticus (Fig. 7b). Nissl (paraffin). 
TABLE I

CHEMICAL ANALYSIS OF THE BRAIN AFTER FORMALIN FIXATION $^{1}$

\begin{tabular}{|c|c|c|c|c|}
\hline & \multicolumn{2}{|c|}{ White Matter } & \multicolumn{2}{|l|}{ Cortex } \\
\hline & Normal & Case 2 & Normal & Case 2 \\
\hline $\mathrm{H}_{2} \mathrm{O}$ & $72 \cdot 4$ & $86 \cdot 0$ & $86 \cdot 6$ & $87 \cdot 5$ \\
\hline Total lipid & $42 \cdot 0$ & $32 \cdot 0$ & $26 \cdot 0$ & $31 \cdot 0$ \\
\hline Total lipid hexose & $2 \cdot 10$ & 0.62 & 0.82 & 0.55 \\
\hline Neutral hexose & $1 \cdot 25$ & 0.26 & $0 \cdot 16$ & 0.06 \\
\hline Lipid hexosamine & 0.051 & 0.083 & $0 \cdot 168$ & 0.074 \\
\hline Residual hexosamine & 0.364 & 0.647 & 0.422 & 0.626 \\
\hline Total hexosamine & 0.415 & 0.730 & 0.590 & $0 \cdot 700$ \\
\hline Neuramic acid & $0 \cdot 132$ & $0 \cdot 120$ & 0.427 & $0 \cdot 201$ \\
\hline Lipid sulphur & $0 \cdot 122$ & 0.081 & 0.075 & 0.045 \\
\hline Cholesterol free & $10 \cdot 5$ & $5 \cdot 6$ & $5 \cdot 1$ & $4 \cdot 9$ \\
\hline Cholesterol ester & $0 \cdot 1$ & 0.7 & Nil & $0 \cdot 1$ \\
\hline Total phospholipid & $15 \cdot 0$ & $17 \cdot 9$ & $14 \cdot 4$ & $19 \cdot 0$ \\
\hline Lecithin & $7 \cdot 1$ & $7 \cdot 4$ & 6.8 & $8 \cdot 0$ \\
\hline
\end{tabular}

${ }^{1}$ All values (except water) in g./100 g. of dry tissue

\section{CHEMISTRY}

The analytical methods were those referred to in previous papers (Tingey and Edgar, 1963), and the results are set out in Table I. Comparison is made with the brain of a normal child aged 12 months. As Table I shows, there is evidence of demyelination of the cerebral white matter and cortex in the reduced levels of cholesterol and neutral hexose (cerebroside). The chemical estimation of sphingomyelin was not satisfactory in this case, but thin-layer chromatography showed it to be reduced in both cortex and white matter. The high total hexosamine is consistent with a leucodystrophy, though the value of $0.083 \%$ for the lipid hexosamine does not reach the level of approximately $0 \cdot 1 \%$, which, according to Edgar (1961), would strongly indicate a leucodystrophy. (In his analysis of five cases of spongy degeneration Edgar found only one case with raised lipid hexosamine levels.)

\section{DISCUSSION}

Study of the brain of one of the affected sisters revealed relatively minor changes of the grey matter, the severe cell loss in Ammon's horn and the homogenizing changes in the Purkinje cells being attributable to the epileptic convulsions, which had been particularly stormy in the last days of life. More significant of leucodystrophy is the selective atrophy of the granular layer of the cerebellum, a change which has been described in metachromatic and sudanophilic forms (Norman, Tingey, Valentine, and Danby, 1962).

More prominent were the changes affecting the cerebral white matter, namely, spongy vacuolation, demyelination, fibrillary gliosis, and large amounts of sudanophilic products in certain demyelinated areas. Vacuolation and defective myelination of the cerebral white matter are important features of infantile spongy degeneration of the van Bogaert and Bertrand type, a condition often associated with progressive enlargement of the head and heavy brains (Banker, Robertson, and Victor, 1964; Hogan and Richardson, 1965). Similar features have also been noted in other conditions, notably maple syrup urine disease and homocystinuria (Crome, Dutton, and Ross, 1961; Silberman, Dancis, and Feigin, 1961; Chou and Waisman, 1965) and in cases of infantile spasm and hypsarrhythmia (Poser and Low, 1960). In the present cases large amounts of sudanophilic products, evidence of active demyelination, were present, a finding, which, together with a raised level of lipid and non-lipid hexosamine obtained by chemical studies, points in the direction of sudanophilic leucodystrophy.

Alzheimer's type II glial cells and spongy change prominent in the subcortex, which are essential features of van Bogaert and Bertrand disease, were not observed.

Infantile spasms have been observed in a familial case of infantile spongy degeneration (van Bogaert and Bertrand, 1949) as well as in maple syrup urine disease (Allen, 1964). This variety of epilepsy has long been regarded as a clinical syndrome and has been subdivided into two groups, symptomatic and cryptogenic. In the former, development is retarded before the onset of the spasms, and a pathological process might be recognizable; in the latter, development is apparently normal before the onset of spasms (Jeavons and Bower, 1964).

Recent neuropathological data (Bignami, Zappella, and Benedetti, 1964) have provided further evidence that this form of epilepsy can be present in a variety of infantile encephalopathies such as gross congenital malformations, tuberous sclerosis, metabolic diseases, sequelae of birth injuries, and infections of the central nervous system. In some of these cases, as well as in one of the sisters described here, development was apparently normal until the onset of the spasms.

\section{SUMMARY}

Two cases of infantile spasms and hypsarrhythmia occurring in siblings are reported. In one of them study of the brain revealed severe vacuolation and demyelination of the cerebral white matter, with large amounts of sudanophilic products and with raised levels of lipid hexosamines and non-lipid hexosamines. These changes were thought to be compatible with a pathological diagnosis of sudanophilic leucodystrophy.

We are grateful to Dr. R. M. Norman for his advice. 


\section{REFERENCES ${ }^{1}$}

Allen, N. (1964). Developmental and degenerative diseases of the brain. In Pediatric Neurology, p. 248, edited by T. W. Farmer, Harper and Row, New York.

Banker, B. Q., Robertson, J. T., and Victor, M. (1964). Spongy degeneration of the central nervous system in infancy. Neurology (Minneap.), 14, 981-1001.

Bignami, A., Zappella, M., and Benedetti, P. (1964). Infantile spasms with hypsarrhythmia: a pathological study. Helv. paediat. Acta, 19, 326-342.

Chou, S. M., and Waisman, H. A. (1965). Spongy degeneration of the central nervous system. Arch. Path., 79, 357-363.

Crome, L., Dutton, G., and Ross, C. F. (1961). Maple syrup urine disease. J. Path. Bact., 81, 379-384.

Edgar, G. W. F. (1961). Neurochemical aspects of leucodystrophy. Psychiat. Neurol. Neurochir. (Amst.), 64, 28-36.

Hogan, G. R., and Richardson, E. P. (1965). Spongy degeneration of the nervous system (Canavan's disease). Pediatrics, 35, 284-294.

Jeavons, P. M. and Bower, B. D. (1964). Infantile Spasms. Clinics in Developmental Medicine, No. 15 (Spastics Society). Heinemann, London.
Norman, R. M., Tingey, A. H., Valentine, J. C., and Danby, T. A (1962). Sudanophil leucodystrophy in a pachygyric brain. J. Neurol. Neurosurg. Psychiat., 25, 363-369.

Poser, C. M., and Low, N. L. (1960). Autopsy findings in three cases of hypsarhythmia (infantile spasms with mental retardation) Acta pediat. (Uppsala), 49, 695-706.

Silberman, J., Dancis, J., and Feigin, I. (1961). Neuropathological observations in maple syrup urine disease. Arch. Neurol. (Chic.), 5, 351-363.

Tingey, A. H., and Edgar, G. W. F. (1963). A contribution to the chemistry of the leucodystrophies. J. Neurochem., 10, 817-823.

Van Bogaert, L., and Bertrand, I. (1949). Sur une idiotie familiale avec dégénerescence spongieuse du névraxe. Acta neurol. belg., 49, 572-587.

${ }^{1}$ Since this paper went to press the following paper has been brought to our notice:

Cotte-Rittaud, M. R., and Delfin, J. (1965). Présentation d'une observation familial de maladie de spasmes en flexion avec Hypsarythmia. Rev. neurol. 112, 301-303.

\section{政}

